\title{
Applying Bengtson's Model of Intergenerational Solidarity to Czech Caring Families ${ }^{1}$
}

\author{
Hynek Jerabek ${ }^{2}$ \\ Charles University, Faculty of Arts \& Faculty of Social Sciences

\begin{abstract}
Applying Bengtson's Model of Intergenerational Solidarity to Czech Caring Families. This paper links two research fields: elderly care in families and intergenerational solidarity. Its aim is to apply Bengtson's general theory of intergenerational solidarity to a specific sample of families currently caring for an elderly family member. Is it possible to apply Bengton's general theory to a generation of families caring for elderly parents? We compared our findings with the results of studies in the US and the Netherlands and found simillar types of families. We also developed and tested a unidimensional scale for measuring family cohesion as a specification of Bengtson's classic model. Success in comparison offers a chance for generalization of our findings also in other countries under specific circumstances.

Sociológia 2019, Vol. 51 (No. 6: 584-602)

https://doi.org/10.31577/sociologia.2019.51.6.24
\end{abstract}

Key words: Caregiving; family relations; intergenerational relations; multigenerational bonds; family typology; intergenerational solidarity; V. L. Bengtson; family cohesion

\section{Introduction: The research question and theoretical background}

The aim of this study was to apply Bengtson's six-dimensional model of intergenerational solidarity to Czech families providing elderly care. Our main question is: Can we apply Bengtson's general theory of intergenerational solidarity to a generation of families caring for their elderly parents? We applied Bengtson's classic model in a study of Czech families caring for an elderly family member.

Vern L. Bengtson and his team started with a simple model of 'multigenerational bonds' or 'intergenerational ties' in which 'family solidarity ... can be viewed as interaction between family members in those spheres of life that involve association, consensus and affection' (Bengtson et al. 1976: 247).

The theory for the development of this model is described in detail in (Bengtson - Roberts 1991). Bengtson and Roberts in this principal paper set out an improved model that in its ideal, most comprehensive form works with six dimensions of intergenerational solidarity: 1) associational solidarity; 2) affectual solidarity; 3) consensual solidarity; 4) functional solidarity; 5) normative solidarity; 6) structural solidarity. (Bengtson - Roberts 1991) Vern

\footnotetext{
1 This work was supported by a project of the Czech Science Foundation No. 16-07931S Needs Assessment of Family Caregivers of Elderly and is also the outcome of work conducted under the programme Progres Q15 - part of the Faculty of Social Sciences, Charles University.

2 Address: Prof. PhDr. Hynek Jerabek, CSc., Faculty of Arts \& Faculty of Social Sciences, Charles University, U Krize 8, 15801 Praha 5, Czech Republic. E-mail: hynek.jerabek@gmail.com
} 
Bengtson and his coauthor emphasised that: '... normative solidarity expectations that adult children and aging parents should perform familial roles and obligations - makes important contributions to affectual and associational solidarity, as suggested by Tönnies (1887 - 1957)' (Bengtson - Roberts 1991: 867). Also in another paper, written in the same year, Roberts, Richards and Bengtson confirmed the role and importance of normative solidarity in the model: 'Higher levels of normative solidarity are anticipated to lead to higher levels of intergenerational affection, association and exchange.' (Roberts et al. 1991: 23)

In an earlier conceptualisation of intergenerational ties Nye and Rushing listed 'goal integration' among the six dimensions of 'family integration' (Nye - Rushing 1969). These authors expected that 'goal integration' represented the second component of normative solidarity. To the first, 'family obligation', they expected to add 'the concepts of interdependence and goal integration'. They argued that this approach was consistent with the original theory of Émile Durkheim, who distinguished two types of solidarity between people 'mechanical solidarity' and 'organic solidarity' (Durkheim 1893/1933). (Compare with Jerabek 2008: 137-145)

Our study was motivated by a statement made by Roberts and Bengtson. They wrote: ' $[R]$ eplicating previous findings in different contexts also allows more confident specification of the conditions under which a theory is applicable' (Roberts - Bengtson 1990: S12). Inspired by this, we organized a survey of a specific population of Czech families caring in a home environment for a senior who needs intensive and usually intimate care.

When we pre-tested our sample of caring families, we found intergenerational solidarity to be sufficiently strong in all the dimensions of Bengtson's model that we measured. At the same time the individual indexes correlated with each other. Under these specific circumstances we tried to construct an unidimensional Family Cohesion Index as a composite scale for all the measured aspects of intergenerational solidarity.

We expected that it would also be possible to observe this 'unidimensional family cohesion' in other countries for family groups that fulfill the specifications of the theory.

\section{Bengtson's theory of intergenerational solidarity}

Vern L. Bengtson and his coauthors described the six-dimensional model as follows:

1) Affectual solidarity refers to the emotions that one family member shows for another (Bengtson 2001: 8). 
2) Associational solidarity is usually measured by the respondent's response to the question: 'How often do you see or have contact with your (mother) (father)?' (Silverstein - Bengtson 1997: 454).

3) Consensual solidarity means that a son or daughter has similar opinions, values, and orientations to those of their mother or father (Bengtson 2001: 8).

4) Functional solidarity reflects: 'the giving and receiving of support across generations, including exchange of both instrumental assets and services as well as emotional support.' (Bengtson 2001: 8).

5) Normative solidarity refers to the 'ratings of importance of family and intergenerational roles' or the 'rating of the strength of filial obligations' (Bengtson - Roberts 1991: 857).

6) Structural solidarity expresses the specific conditions of the feasibility, the opportunity, and the possibility of assistance and support. (Silverstein Bengtson 1997: 454).

This six-dimensional model was used and its validity was confirmed in the 'German Ageing Survey' (Kohli - Künemund eds. 2000; Hoff 2007), in the international OASIS study, in which Norway, England, Germany, Spain and Israel participated (Daatland - Herlofson 2001; Bengtson - Löwenstein 2003), in a study of the population of the Netherlands (van Gaalen - Dykstra 2006), and in the international SHARE study (Hank 2007). This model has thus been at the theoretical centre of almost every attempt to measure solidarity in the decades since the 1980's (Löwenstein et al. 2001: 25; Giarrusso et al. 2005: 415).

\section{An alternative concept of ambivalence and Bengtson's response}

Since the very beginning of 'solidarity and integration studies', theoreticians and empirical researchers have given consideration to the fact that not only solidarity ties but also conflicts are present in multigenerational relationships. The study of solidarity ties helps to provide an understanding of the linkages between generations. Nevertheless, when the six-dimensional model of solidarity was enjoying its heyday in research theory, the very concept of solidarity was criticised by phenomenologists and critical sociologists, who challenged it on the grounds of the concept of ambivalence (Lüscher - Pillemer 1998; Connidis - McMullin 2002). Both phenomenologists and critical sociologists emphasised the constant presence of positive and negative ties and attitudes among family members.

In response to the more applicable critical sociological concept of ambivalence developed by (Connidis - McMullin 2002), Bengtson, Giarrusso, Mabry and Silverstein defended the model of intergenerational solidarity by pointing out that solidarity, conflict, and ambivalence are complementary 
perspectives of intergenerational relationships. They referred to small group theory in the field of psychology and research in the sociology of the family to defend their model of intergenerational solidarity and argued that research in those fields found that the presence of conflict does not exclude the existence of solidarity in the family, which is what forms the natural foundation of family integration - it sheds light on the bonds that hold a family together (Bengtson et al. 2002: 571).

\section{Applying Bengtson's model under specific conditions}

The assumptions of socio-psychological conceptions of family solidarity The aim of our specific application of Bengtson's model of intergenerational solidarity would be to test how Bengtson's general theory works when all six dimensions of intergenerational solidarity are present at the same time, which would mean a strong likelihood that the conditions on which the theory of group solidarity is predicated are met.

According to sociological and socio-psychological theory (see Homans 1950; Roberts et al. 1991), the following assumptions apply to cohesive small groups:

1. strong emotional bonds between group members,

2. frequent contact,

3. mutual assistance among group members,

4. group members share values and opinions,

5. feel an obligation to and responsibility for the group as a whole,

6. group members are committed to their group even at the cost of personal expense.

From previous research on Czech caring families we know that family members providing elderly care tend to be characterised by a strong sense of 'familial obligation' (assumption 5) and by 'altruistic behaviour' (assumption 6) (Jerabek et al. 2013: 70-125). An essential precondition for the formation of cohesive ties in families whose members are caring for a senior is the existence of an acute need for personal long-term care for that senior. (Jerabek et al. 2013: 82-83, 95-96) In their very first study Bengtson, Olander and Haddad anticipated the significance of this type of personal dependence. They presented a multivariate model of solidarity between the older and the middle generations and illustrated the causal dependence of 'helping behaviour' on the 'dependency needs of the elderly' (Bengtson et al. 1976: 258). This relationship was confirmed by Roberts and Bengtson. (Roberts - Bengtson 1990: S13) The seniors in Czech caring families were also found to most likely require a time-demanding form of personal family care (Jerabek 2009; Jerabek 2014: 162-168) and Czech caring families also exhibited strong emotional ties, frequent association, consensus, and the provision of care. A sample of such 
Czech families providing informal care for a family member could therefore be a suitable basis on which to conduct a specification test for Bengtson's model.

\section{Czech data}

We tried to create a representative sample of seniors receiving care and the families that care for them. We don't have a national register of caring families or a register of elderly persons who need substantial personal care. Therefore, we used an alternative approach to select the families for our study. As seniors grow older, the percentage who become dependent on care increases. So our sampling process focused on elderly men aged 74 and older and women aged 79 and older. Given how demanding informal family care for seniors is, we selected only couples providing care (i.e. a married couple or a couple living in a partnership) from the generation of the seniors' children - that is, a daughter, son, daughter-in-law, or son-in-law between the ages of 40 and 65. And one of the conditions was that caring members of these families spent at least 12 hours a week providing care on what they described as a regular basis. As a control category we also measured the seniors' BADL and IADL scores. (Jerabek et al. 2013: 70,75; Katz 1983; Manton - Soldo 1992: 212) We interviewed 413 main carers in a structured interview that lasted on average one hour. All regions, and rural and urban communities were proportionally represented in our sample. Since our interest was in intergenerational solidarity, we focused on adult children providing care and deliberately left aside care provided by the senior's partner alone - an occurrence that is common and that we have generally also observed.

\section{Our measurement model}

We measured selected dimensions of intergenerational solidarity and prepared five indexes.

- index of emotional solidarity

- index of past associational solidarity

- index of present associational solidarity

- index of consensual solidarity

- index of functional solidarity ${ }^{3}$

\section{Emotional solidarity}

To calculate the index of emotional solidarity we interviewed our sample of carers and presented them with a battery of eight items ${ }^{4}$ expressing the

\footnotetext{
3 Details of the construction of all partial indexes we took over from the description in the research report (Jerabek et al. 2013: 190-1; 206-7; 221-2; 233-5; 240-8).
} 
reciprocity of emotional ties between the adults providing care and the senior receiving care. The most significant item from the list was the statement: ' $\mathrm{s} / \mathrm{h}$ e understands my real needs.' The responses to the items were measured on a scale: 'very often' $=2$, 'sometimes' $=1$, 'seldom' $=-1$ and 'never or almost never' $=-2$. Factor score from these items formed the basis of the first part of our index of emotional solidarity. The second part we obtained from the two pairs of statements measuring the subjective expression of the strength of feeling the respondent felt towards the senior receiving care and the senior's reciprocity of feeling towards the respondent, and from the next pair of questions seeking an appraisal of the feelings of other family members towards the senior and the senior towards them. Here we applied the ordinal scale from 'weak' $=1$ point to 'strong' $=10$ points. We also used there the factor score, because the loadings of these items on the factor were very strong $(r=0.86-$ 0.89 ). Finally, we summarised the standardised values of these two factor scores. The sum of the family's emotions was expressed as a standardised measure on a scale ranging from minimum $=0$ to maximum $=100$ points (Compare Jerabek et al. 2013: 190, 241-3).

\section{Past associational solidarity and present associational solidarity}

The practice of family care altered the frequency of contact between the adult caring childern and the senior. Therefore, in measuring associational solidarity we differentiated between the present and past situation in the family and created two indexes, the index of 'past associational solidarity' and the index of 'present associational solidarity', using almost the same approach, but based on data on the frequence of personal contact and telephone contact between the carer and the senior in the present and in the past. We used the same approach as V. L. Bengtson's team and we summed up the amount of time the respondents and seniors spent in personal contact and in contact by phone ${ }^{5}$. Given that a significant number of the families shared a home with the senior (approximatelly $50 \%$ ) they were caring for, we did not use a numerical scale with the number of hours of contact between the adult child giving care and the senior, but instead created two ordinal scales, one for 'past associational solidarity' and one for 'present associational solidarity'. The scale for past associational solidarity had four categories: up to 3 hours a week; up to 10 hours a week; more than 10 hours a week but they did not live together; they lived together. The scale for present associational solidarity had just three categories: up to 10 hours a week; more than 10 hours a week but they do not live together; they

\footnotetext{
${ }^{4}$ The reciprocity items are: a) s/he respects my feelings; b) s/he asks me about my problems and worries; c) s/he respects my time; d) s/he trusts me; e) s/he confides in me with his/her problems and worries; f) s/he understands my real needs; g) I have the feeling that s/he understands me; h) s/he confides in me with his/her problems and worries.

5 A detailed analysis is provided by Romana Trusinová (see Jerabek et al. 2013: 205)
} 
live together. The evaluation based on the respondent's subjective assessment of the frequence of contact (indicated on a scale from 1 to 10) was also added to both indexes. The two resulting indexes were then standardised to a scale of 0 to 100 points (compare Jerabek et al. 2013: 206-7).

\section{Consensual solidarity}

To calculate the index of 'consensual solidarity' we used a battery of eight questions ${ }^{6}$ aimed at determining the level of consensus between the carer and the senior for example, with regard to their priorities and feelings about important issues and an evalution of the care provided to the senior, etc. In the second battery of four questions carers stated on a scale from 1 to 10 how much they agreed with the senior's principles in life, how much the senior agreed with the carers' principles in life, and then the same two questions again but applied reciprocally to the senior and the rest of the family. The resulting summary scale had a symmetrical bell-shaped distribution with a large share of values around the centre of the scale. Again we standardised the scale from 0 to 100 points (Compare (Jerabek et al. 2013: 221-2, 245).

\section{Functional solidarity}

We grounded the measurement of functional solidarity in a new conceptualisation. We based it on the relationship between the demand and supply of help for the elderly. The index of 'functional solidarity' was calculated from a comparison of the care actually provided and the care needs that were determined $^{7}$ independently from the BADL (basic activities of daily living) index score and supported by the IADL (instrumental activities of daily living) index score. Identical items describing the forms of care provided and the forms of care required - for example, doing the shopping for or feeding the care recipient - were compared back to back for the provider and the recipient; in other words, in each case a comparison was made of how many activities the senior needed help with and in how many of them the family's main caregiver provided care. The same comparison was conducted also for the rest of the family taken as a single unit. This created a relative partial index of functional solidarity for the main caregiver and a similar relative partial index for the rest of the family. These two scores were summed for each senior and standardised

\footnotetext{
${ }^{6}$ The exact wording of the questions is: 'What exactly do you generally disagree over?: a) important decisions; b) how to provide him/her with assistance; c) how to spend the time when we're together; d) priorities and goals and what things are important in life; e) expressing emotions, feelings; f) the amount of time we spend together/how much time we should spend together; g) care arrangements, that is, who specifically is to provide the care and in what way; h) my professional career. The higher the index score, the less disagreement there is (see Jerabek et al. 2013: 244).

7 The following nine items from the whole list were the ones cited most frequently: 'a) cooking and prepraring food for the care recipient; b) feeding the care recipient; c) preparing and administering medication; d) doing the shopping for the care recipient; e) performing ordinary housework; f) doing the laundry; g) helping with personal hygiene and getting dressed; $h$ ) tidying up the care recipient's bed; i) helping the care recipient to get around and to walk, or if necessary, physically assisting an immobile care recipient' (compare Jerabek et al. 2013: 232-233).
} 
to a scale of 0 to 100 points to create an 'index of functional solidarity' (Compare Jerabek et al. 2013: 233-5).

It was also necessary to test whether the correlations between individual dimensions of intergenerational solidarity are sufficient for us to create and calculate a total index. It was not possible to do this in the studies by (Atkinson et al. 1986) and Roberts and Bengtson (1990) as the strength of the correlations between the measured dimensions of intergenerational solidarity was too weak in these American studies. Our sample consisted of Czech families caring for elderly members who needed intensive personal care, and we assumed, and also confirmed, that in this case the correlations between individual components of intergenerational solidarity are stronger. Because of these strong correlations indicating the existence of close relationships we were able to use a population of Czech families to measure unidimensional family cohesion (compare Jerabek et al. 2013: 248-50).

\section{The Family Cohesion Index}

Our assumption that stronger correlations between the individual components of intergenerational solidarity will be found in families caring for a senior was confirmed (see Table 1). Therefore we created a unidimensional Family Cohesion Index (FCI).

\section{Table 1: Correlations between dimensions of intergenerational solidarity}

\begin{tabular}{lcccc}
\hline Correlation of indexes & $\begin{array}{c}\text { Emotional } \\
\text { solidarity index }\end{array}$ & $\begin{array}{c}\text { Consensus } \\
\text { solidarity index }\end{array}$ & $\begin{array}{c}\text { Functional } \\
\text { solidarity } \\
\text { index }\end{array}$ & $\begin{array}{c}\text { Index of present } \\
\text { associational } \\
\text { solidarity }\end{array}$ \\
\hline $\begin{array}{l}\text { Consensus solidarity index } \\
\text { Functional solidarity index }\end{array}$ & 0.61 & 0.52 & 0.44 & 0.63 \\
$\begin{array}{l}\text { Index of present association } \\
\text { solidarity }\end{array}$ & 0.38 & 0.40 & 0.50 & 0.79 \\
$\begin{array}{l}\text { Index of past association } \\
\text { solidarity }\end{array}$ & 0.32 & & & \\
\hline
\end{tabular}

Source: 'Family Cohesion in Elderly Care 2010’.

In constructing the FCI it made sense to take into account to what extent the individual components (dimensions) of intergenerational solidarity in the given family contribute to the family's overall social solidarity. From the in-depth interviews that we conducted in the year before the main survey with the main carers in 27 families we learned that there were significant differences between families in terms of how they evaluate which component of solidarity contributes more to family solidarity and which less (Jerabek et al. 2013: 34-36). 
In the main survey using standardised questions for each dimension of intergenerational solidarity we asked each respondent (the main caring person) how much relevance he or she assigns to each particular dimension. In this way we were able to individualise the weights for the dimensions. This approach made our measurements more valid and more realistic. We created a weighted Family Cohesion Index. Each main carer indicated for each of the five dimensions how important the given dimension was for their family. We used weights ranging from 'completely unimportant' $=0$ to 'very important' $=3$. We added up the scores of the individual indexes multiplied by the weight and divided the sum by the number of dimensions. A score on the total Family Cohesion Index was calculated for each family this way (compare Jerabek et al. 2013: 250-53). Figure 1 shows the distribution of the FCI.

Figure 1: The Family Cohesion Index (FCI)

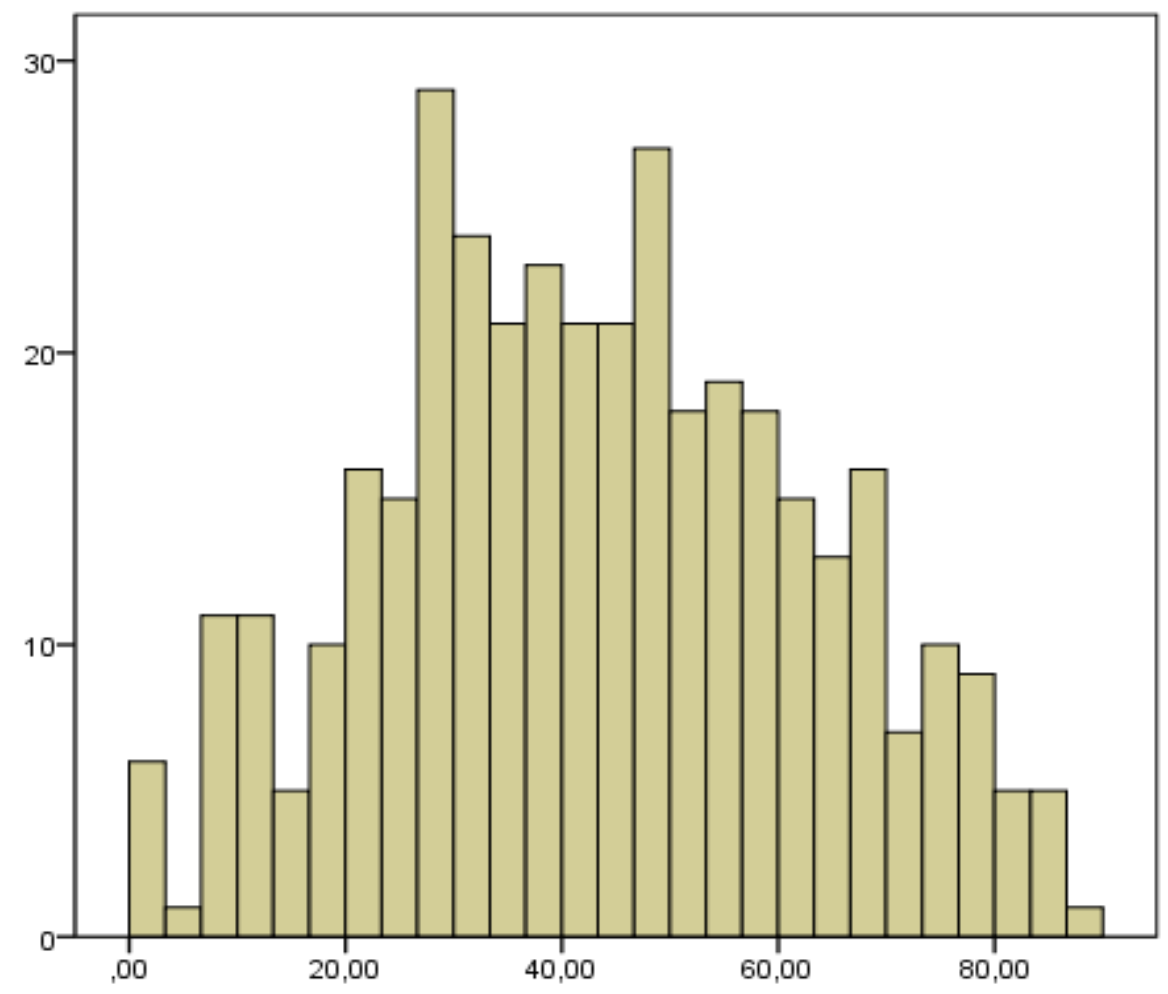

Source: 'Family Cohesion in Elderly Care 2010’.

The results of this specification test confirm that Bengtson's model of intergenerational solidarity is valid also when applied to a specific group of 
Czech families that are already providing 'informal care for their elderly in home conditions', i.e. under the same circumstances that socio-psychological small group theory and research on the family in sociology stipulate as the preconditions of family cohesion. Bengtson's multidimensional model was robust enough and shown apply even in its limit - unidimensional - version.

\section{A comparison of Czech, US and EU families}

\section{A typology of US and EU families}

We did not expect Czech caring families to be in some respect completely different from families caring for seniors in other countries. Therefore, we looked at the Czech families in our study to see if we could identify any that were similar in type to those identified by researchers in other countries. Two directions of comparison suggested themselves. Silverstein and Bengtson came up with a well-specified and clearly described typology of distinct and internally homogeneous classes of families in the United States (Silverstein Bengtson 1997: 442-451). Pearl Dykstra and R. van Gaalen published the results of their representative study formulated as hypogeneous types of families in the Netherlands, a study in which they used the same methodology as the US researchers and whose typology is comparable to our own (van Gaalen - Dykstra 2006: 957). The main reason these two studies are suited for comparison is that the patterns of regularities by which individual types of families differ in the US and in the Netherlands are based on roughly similar dimensions of intergenerational solidarity as in the Czech case. Moreover, the author of the Dutch study, Pearl Dykstra herself, compared the results of her study to those of the US study.

The study by Silverstein and Bengtson distinguished the following five types of families: 1) 'tight-knit' - a traditional multigenerational family whose members are emotionally close, are in frequent contact, and engage in mutual assistance; 2) 'sociable' - a multigenerational family whose members are in frequent contact and are emotionally close, but do not engage in mutual assistance; 3) 'intimate but distant' - this type of family is characterised by strong emotional ties and similarity of opinions, but lacks geographical proximity, frequency of contact, and members do not engage in the provision and receipt of mutual assistance; 4) 'obligatory' - this family is characterised by geographical proximity and occasional contact and an average level of intergenerational assistance, but members do not have strong emotional ties or similarity of opinions; 5) 'detached' - this type of family lacks emotional ties, geographical proximity, and mutual assistance (Silverstein - Bengtson 1997: 442, 444). Silverstein and Bengtson expected that family types 2) and 3), described as 'sociable' and 'intimate but distant', have the potential to engage 
in the provision and receipt of mutual assistance should the need arise (Silverstein - Bengtson 1997: 450-451).

Pearl Dykstra analysed Dutch families and came up with a typology similar to that of V. L. Bengtson. Her 'harmonious' type of family is characterised by frequent contact, emotional ties, and few conflicts; the 'ambivalent' type is characterised by frequent contact, the highest level of practical assistance given and received, but also a high level of conflict. The 'obligatory' type is characterised by frequent face-to-face contact and practical assistance, but a lack of any significant emotional support; the 'affective' type is characterised by emotional support provided remotely, but no practical support and no face-toface contact; and the 'discordant' type typically experiences conflict in its personal affairs, provides no practical assistance and no emotional support, and has no contact of any kind (van Gaalen - Dykstra 2006: 953-954).

\section{Table 2: Types of families $\mathbf{A}-\mathbf{F}$ and their indices of intergenerational solidarity}

\begin{tabular}{|c|c|c|c|c|c|c|}
\hline \multirow[b]{2}{*}{ Indices } & \multicolumn{6}{|c|}{ Family types } \\
\hline & $\begin{array}{c}\text { A } \\
\text { detached }\end{array}$ & $\begin{array}{c}\text { B } \\
\text { associational }\end{array}$ & $\begin{array}{c}\text { C } \\
\text { intimate but } \\
\text { distant }\end{array}$ & $\begin{array}{c}\text { D } \\
\text { socially-driven } \\
\text { care }\end{array}$ & $\begin{array}{c}\text { E } \\
\text { emotionally- } \\
\text { driven care }\end{array}$ & $\stackrel{\text { F }}{\text { tight-knit }}$ \\
\hline $\begin{array}{l}\text { Family Cohesion } \\
\text { Index }\end{array}$ & 7 & 22 & 27 & 39 & 46 & 66 \\
\hline $\begin{array}{l}\text { Functional } \\
\text { solidarity index }\end{array}$ & 19 & 34 & 38 & 46 & 47 & 57 \\
\hline $\begin{array}{l}\text { Emotional solidarity } \\
\text { index }\end{array}$ & 36 & 43 & 64 & 54 & 79 & 84 \\
\hline $\begin{array}{l}\text { Consensus } \\
\text { solidarity index }\end{array}$ & 29 & 33 & 46 & 46 & 59 & 68 \\
\hline $\begin{array}{l}\text { Index of past } \\
\text { association } \\
\text { solidarity }\end{array}$ & 14 & 54 & 33 & 74 & 56 & 86 \\
\hline $\begin{array}{l}\text { Index of present } \\
\text { association } \\
\text { solidarity }\end{array}$ & 15 & 54 & 39 & 82 & 67 & 91 \\
\hline
\end{tabular}

Source: 'Family Cohesion in Elderly Care 2010'.

Pearl Dykstra compared her results with the results of Silverstein and Bengtson (1997) and found that the 'harmonious' type corresponds to Bentson's 'sociable' type, and the 'obligatory' types in both typologies are similar. The 'ambivalent' type corresponds to Bengtson's 'tight-knit' type with 
close ties of every kind, the 'affective' type corresponds to Bengtson's 'intimate but distant' type. And finally the 'discordant' type on the whole matches the 'detached' type in Silverstein and Bengtson's typology (van Gaalen - Dykstra 2006: 957).

A typology of Czech caring families ${ }^{8}$

In the Table 2 is a typology of Czech families by FCI scores - increasing from A to F:

A. detached $=$ all ties are weak $\&$ no care

B. associational = contacts, some emotion \& limited care

C. intimate but distant $=$ emotion, weak contacts \& limited care

D. socially-driven care $=$ past $\&$ present contacts $\&$ care

E. emotionally-driven care $=$ emotion, consensus \& care

F. tight-knit $=$ all ties strong $\&$ intensive care

Similarities of Czech, US \& EU family types

The Czech Type F or tight-knit family corresponds to the 'tight-knit' type in the study by Silverstein and Bengtson and to the 'ambivalent' type in the Dutch study by Pearl Dykstra. The Type F or tight-knit family typically provides intensive care for a senior and has strong ties in every dimension. The Czech Type A or detached family, in which no care is provided and all the ties are weak, is almost identical to the 'detached' type observed in the study of American families and to the 'discordant' type described in Dykstra's Dutch study (van Gaalen - Dykstra 2006: 957). The third Czech type that significantly resembles types identified in the results of studies in other countries is Type $\mathrm{C}$ - intimate but distant, which is characterised by strong emotions and consensus, limited contact, and limited care. It is almost identical to the 'intimate but distant' type in the study by Silverstein and Bengtson (Silverstein - Bengtson 1997: 450-451) and the 'affective' type in the study by Dykstra.

Two specific types of Czech families and their motivations for caring Alongside the Czech family types that are similar to families in the US and the Netherlands, we identified two interesting types of Czech caring families for which we could find no comparable group of families in the US or in the Netherlands. Both of these family types are however relatively common in Czech society (approximately one-quarter of caring families fall into each of these types) and in practical terms they are easy to explain. They differ from Type F, 'tight knit', and the motivation for caring for a senior in the family

\footnotetext{
${ }^{8}$ We used the method of cluster analysis that results in 6 types of caring families. This variant is the best for enabling a comparison with the US and the Dutch typologies.
} 
does not come from all the important dimensions of intergenerational ties operating at the same time, but is based on different dimensions for each of the two types, and therefore the mechanisms that lead the family to care for a senior in the family probably differ also. We named the first of these specifically Czech types the 'Type D family', marked by 'socially-driven care', a type characterised by frequent contact in the past and no less frequent contact in the present, and in which the senior typically has substantial care needs. We believe that the family's motivation to care for their senior primarily stems from frequent past contact with the senior. The frequent contact in the present probably revolves around the provision of intensive or regular care. The second specifically Czech type is 'Type E', marked by what we called 'emotionallydriven care'. In this type, strong emotional ties and consensus are what motivate the the family to provide care. Here again the senior has substantial care needs or is even dependent on care.

\section{Discussion}

The Family Cohesion Index and a typology of Czech families

Family types with specific patterns of stronger and weaker correlations between dimensions of family solidarity have different motivations for providing personal care for their elderly members. These families follow different paths to becoming cohesive families.

The total score that a family gets on the Family Cohesion Index is the combined result of the different factors that make families cohesive. Generally, strong correlations between all these dimensions are signs of unidimensionality. All the relatively strong correlations between these dimensions of intergenerational solidarity, however, are not just evidence of the existence of a group of families that is characterised by very strong ties between all the dimensions at the same time, but also, hypothetically, could indicate that there exists a mixture of several family groups or family types with different patterns of solidarity bonds.

Some of these groups are characterised by strong correlations between two or three of these dimensions and some others show a different pattern of stronger correlations or ties between the other dimensions. Strong ties between one set of dimensions are evidence of one mechanism at work, and strong ties between a different set of two or three dimensions are evidence of another mechanism at work. D. Mangen and K. McChesney wrote in 1988 that '... families develop unique patterns of solidarity within the intergenerational system...' (Mangen et al. 1988: 220). At present we do not have enough evidence about these mechanisms, but the evidence we have is based on the patterns of stronger and weaker ties in subgroups of families. 
In our specific case we were interested in what patterns of intergenerational relationships led families to provide elderly care. These patterns can indicate some principal mechanisms that are valid for types of families with different motivations for caring for elderly family members.

1. What mechanisms motivate families to provide intensive personal care for elderly members? Some families provide an intensive level of care and others provide much less care. Some family members are in frequent contact and contact is important to these families. For other families emotions are of high importance and the members of these families have strong emotional ties. We studied the most frequent patterns of correlations between the dimensions of intergenerational solidarity. Family types can be identified according to these patterns. We expect that different patterns of correlations are connected to different mechanisms that lead families to provide informal care for elderly members.

2. A family's total score on the Family Cohesion Index represented the combined outcome of different mechanisms. There should exist different mechanisms that motivate families to provide elderly care. Families achieve family cohesion by different mechanisms.

Using the Family Cohesion Index in other countries?

Can the Family Cohesion Index be used more generally? We believe that it can. First all the theoretical conditions and circumstances that this sociopsychological theory is predicated on need to be met. There have to be multiple homogeneous groups of families that are in a similar stage of the life cycle. Adult children and elderly family members in need of care are a much more appropriate population for this kind of study than a general sample of the whole population of a country. The second important condition for conducting this kind of study, in our view, is that the seniors in the sample are in serious need of personal care, i.e. they have a relatively high BADL index score. Under these circumstances it would be possible to use this unidimensional concept and the Family Cohesion Index latent variable as a measurement tool in other countries.

Homogeneous family types with comparable scores for individual dimensions of intergenerational solidarity can serve as the basis for comparing patterns of intergenerational solidarity and from there also probably the mechanisms that motivate families to care for their elderly. The FCI (Family Cohesion Index) would be based on all the dimensions of intergenerational solidarity discussed above, but the significance given to each of the dimensions would likely differ. Consequently, the weights for different dimensions would also differ. 


\section{Conclusion}

Theoretical conclusions

This successful validation of Bengtson's six-dimensional model is proof that many groups of researchers of intergenerational family cohesion have been theorising in the right direction. The test that was conducted on a specific Czech population made up of the generation of adult children currently caring for elderly parents confirmed that the theory developed by Vern L. Bengtson and his team is valid. It is consistent with the social theories of É. Durkheim, T. Parsons, R. K. Merton, G. C. Homans and others that it was based on and was conceptualised from. The expected correlations were confirmed. By focusing specifically on a population of seniors in need of care and their adult children caring for them we were able to propose a specific version of Bengtson's general theory and to verify it for a specific generation of carers in the Czech Republic. This provided us with important support for the theory of intergenerational solidarity as a whole. The core of this theory probably applies to any families in which adult children are caring for their elderly parents once the parents begin to require regular, intensive care and assistance. However, the model applies much more generally in the sense of the dimensions of intergenerational solidarity which combinations are expressed sometimes as 'latent forms of cohesion' (Silverstein - Bengtson 1997). In specific situations, when the family ties are predominantly cohesive, the group of families are described as 'tight-knit' family type (Silverstein - Bengtson 1997: 442) or 'ambivalent' type (van Gaalen - Dykstra 2006: 957).

\section{Methodological conclusions}

The typology approach is useful for conducting a comparative analysis of the similarities between families in different countries and cultures. A specification test, and thus validation of Bengtson's theory, can be repeated for conditions in the United States, the Netherlands, Germany or Israel using a homogeneous sample of families or households who are actually caring for their elderly family members with high BADL index. Interrelationships between individual dimensions of solidarity could be relativelly high in these family groups. The results of studies by Merril Silverstein and Vern L. Bengtson (1997) and by R. van Gaalen and Pearl Dykstra (van Gaalen - Dykstra 2006) attest to this.

However, these relationships, usually measured as correlations, need not necessarily be identical across countries. The motivation to help and care for elderly parents will not be the same across cultures, countries and individual families, nor will the underlying mechanisms that lead families to become cohesive. There may be moderately different versions of family solidarity in different cultures and countries. Even in the case of Czech families caring for elderly members we have as yet been unable to uncover and describe the exact 
mechanisms underlying the formation of family solidarity in different types of families.

For the time being we can only make assumptions. The gaps in our understanding could probably best be filled in by conducting a conceptually well prepared international research project that would test on a broader scale the robustness of the basic model and the possibility of variations in the model to reflect the culturally distinct conditions in the US and Europe and the latter's western, central, northern or southern regions, and in other countries as well.

Intergenerational solidarity and a specific theory of family cohesion

In the research this article draws on, a qualitative investigation aimed at understanding the processes of informal family care was combined with a survey to test the correlations between a senior's scores on the BADL and IADL indexes and the amount of time spent on elderly care in a family. This approach proved effective when it was combined with research on intergenerational solidarity and family cohesion. The Family Cohesion Index (FCI) as a unidimensional measure of intergenerational solidarity was developed for our specific case.

In our opinion it proved extremely useful to directly link and connect inquiries in two related areas of applied social research: 'family care for the elderly' and 'intergenerational solidarity'. We believe that linking these directions of study helped us to conceptually validate Bengtson's theory of intergenerational solidarity. This conceptualisation fusing two perspectives on a cohesive family allowed us to carry out a specification test of this general theory on a specific population comprised of Czech families intensively caring for a senior member at home. Equipped with this additional knowledge about the population of caring families we were then able to use a specific version of the general theory of intergenerational solidarity, and in these specific conditions the test of family cohesion confirmed the validity of Bengtson's model.

We are convinced, and in future studies we will attempt to show, that alongside a general theory of intergenerational solidarity there is a specific theory of family cohesion that is also valid. Our research has thus far shown that this specific model applies in the conditions of long-term informal care for seniors in Czech families, on the condition that the senior is dependent on the provision of intensive, regular care. The generally applicable theory of 'intergenerational solidarity' is in this specific case manifested as 'family cohesion'. In our sample this family cohesion was as a rule the precondition for - and was even more often confirmed as an outcome of - family care and intergenerational solidarity. The question is whether our findings, which we 
ascertained for Czech caring families, this model of family cohesion, can be confirmed on a wider scale and vindicate in other countries and cultures.

Hynek Jerabek is a professor of sociology at the Faculty of Social Sciences of Charles University in Prague. Over the last three years he has been participating in work on the project 'A Needs Assessment of the Family Caregivers of Elderly Persons' at the Faculty of Arts of Charles University. He is the author of numerous works in sociological methodology and the history of empirical social research. His most recent book was Paul Lazarsfeld and the Origins of Communications Research published by Routledge in 2017. He was the head of a subproject titled 'Homecare for Elderly Family Members', which was conducted as part of a larger project titled 'Social and Cultural Cohesion' under the leadership of Jiri Musil. He then headed the project 'Family Cohesion in Elderly Care' supported by the Czech Science Foundation. He was also a principal author of the monograph Intergenerational Solidarity in Elderly Care, which was published by SLON publishers in 2013 in Czech.

\section{REFERENCES}

ATKINSON, M. P. - KIVET, V. R. - CAMPBELL, R. T., 1986: Intergenerational Solidarity: An Examination of a Theoretical Model. Journal of Gerontology, 41: 408-416.

BENGTSON, V. L., 2001: Beyond the Nuclear Family: The Increasing Importance of Multigenerational Bonds. Journal of Marriage and Family, 63(1): 1-17.

BENGTSON, V. L. - OLANDER, E. B. - HADDAD, A. A., 1976: The „Generation Gap“ and Aging Family Members: Toward a Conceptual Model. In: Gubrium, J. F. (ed.): Time, Roles and Self in Old Age. Behavioral Publications. Pp. 237-263.

BENGTSON, V. L. - ROBERTS, R. E. L., 1991: Intergenerational Solidarity in Aging Families: An Example of Formal Theory Construction. Journal of Marriage and the Family, 53(4): 856-870.

BENGTSON, V. L. - GIARRUSSO, R. - MABRY, J. B. - SILVERSTEIN, M., 2002: Solidarity, Conflict and Ambivalence: Complementary or Competing Perspectives on Intergenerational Relationships? Journal of Marriage and Family, 64(3): 568577.

BENGTSON, V. L. - LÖWENSTEIN, A. (eds.) 2003: Global Aging and Challenges to Families. OASIS. New York: A de Gruyter.

CONNIDIS, I. A. - McMULLIN, J. A., 2002: Sociological Ambivalence and Family Ties: A Critical Perspective. Journal of Marriage and Family, 64(3): 558-567.

DAATLAND, S. O. - HERLOFSON, K. (eds.) 2001: Ageing International Relations, Care Systems and Quality of Life: An Introduction to the OASIS. Oslo: NOVA Norwegian Social Research.

DURKHEIM, É., 1893/1933: The Division of Labor in Society. New York: Free Press. 
van GAALEN, R. - DYKSTRA, P. A., 2006: Solidarity and Conflict Between Adult Children and Parents: A Latent Class Analysis. Journal of Marriage and Family, 68(4): 947-960.

GIARRUSSO, R. - SILVERSTEIN, M. - GANS, D. - BENGTSON, V. L., 2005: Aging Parents and Adult Children: New Perspectives on Intergenerational Relationships. In: The Cambridge Handbook of Age and Ageing. (ed. Johnson, M. L. - Bengtson, V. L. - Coleman, P. G. - Kirkwood, T. B. L.), Cambridge: Cambridge University Press., pp. 413-421.

HANK, K., 2007: Proximity and Contacts Between Older Parents and Their Children: A European Comparison. Journal of Marriage and Family, 69(1): 157-173.

HOFF, A., 2007: Patterns of intergenerational support in grandparent-grandchild and parent-Schild relationships in Germany. Aging and Society, 27: 643-665.

HOMANS, G. C., 1950: The Human Group. New York: Hartcourt, Brace and World.

JERABEK, H., 2008: Familiäre Altenpflege als Beispiel des sozialen Zusammenhalts. In: Amann, A. - Kolland, F. (Hrsg.): Das erzwungene Paradies des Alters? Fragen an eine Kritische Gerontologie. Wiesbaden: VS Verlag für Sozialwiss., pp. 137161.

JERABEK, H., 2009: Rodinná péče o seniory jako „,práce z lásky“: nové argumenty. (Family Care for Seniors as a 'Labour of Life': New Arguments.) Sociologický časopis, Czech Sociological Review, 45(2): 243-265.

JERABEK, H. et. al., 2013: Mezigenerační solidarita v péči o seniory. (Intergenerational Solidarity in Elderly Care.) (in Czech) Praha: SLON.

JERABEK, H., 2014: Bedürfnisse der Senioren und Familiäre Altenpflege - Beispiel des sozialen Zusammenhalts' (The Needs of the Seniors and Elderly Care in Families - an Example of the Social Cohesion.) In: Amann, A. - Kolland, F. (eds.): Das erzwungene Paradies des Alters? Weitere Fragen an eine kritische Gerontologie. 2. Auflage. Wiesbaden: Springer VS, pp. 149-173.

KATZ, S., 1983: Assesing Self-Maitenance: Activities of Daily Living Mobility and Instrumental Activities of Daily Living. Journal of American Geriatrics Society, Vol. 31, No. 12, pp. 721-727.

KOHLI, M. - KÜNEMUND, H. (eds.) 2000: Die zweite Lebenshälfte. Gesellschaftliche Lage und Partizipation im Spiegel des Alters-Survey. Opladen: Leske+Budrich.

LÖWENSTEIN, A. - KATZ, R. - PRILUTZKI, D. - MELHAUSEN-HASSOEN, D., 2001: The Intergenerational Solidarity Paradigm. In: Daatland, S. O. - Herlofson, K. (eds.): Ageing International Relations, Care Systems and Quality of Life: An Introduction to the OASIS. Oslo: NOVA - Norwegian Social Research, pp. 1130.

LÜSCHER, K. - PILLEMER, K., 1998: Intergenerational Ambivalence: A New Approach to the Study of Parent-Child Relations in Later Life. Journal of Marriage and the Family, 60: 413-425.

MANGEN, D. J. - BENGTSON, V. L. - LANDRY, P. Jr. (eds.) 1988: Measurement of Intergenerational Relations. Newbury Park, CA: Sage Publications. 
MANTON, K. G. - SOLDO, J. G., 1992: Disability and Mortality Among the Oldest old. In: Suzman, R. M. - WILLIS, D. P. - MANTON, K. G. (eds.): The Oldest Old. New York: Oxford Univesity Press, pp. 199-250.

NYE, F. I. - RUSHING, W., 1969: Toward Family Measurement Research. In: Hadden, J. - Borgatta, E. (eds.): Marriage and Family. Illinois: Peacock.

ROBERTS, R. E. L. - BENGTSON, V. L., 1990: Is Intergenerational Solidarity a Unidimensional Construct? A Second Test of a Formal Model. Journal of Gerontology: Social Sciences, 45: 12-20.

ROBERTS, R. E. L. - RICHARDS, L. N. - BENGTSON, V. L., 1991: Intergenerational Solidarity in Families: Untangling the Ties That Bind. Marriage and Family Review, 16(1-2): 11-46.

SILVERSTEIN, M. - BENGTSON, V. L., 1997: Intergenerational Solidarity and the Structure of Adult Child-Parent Relationships in American Families. The American Journal of Sociology, 103(2): 429-460.

TÖNNIES, F., 1887/1957: Community and Society. (Gemeinschat und Gesellschaft) (translated and ed. by C. P. Loomis). East Lansing: Michigan State University Press (orig. publ. 1887).

\section{DATA SOURCES}

'Family Cohesion in Elderly Care 2010': A Survey Conducted by SC\&C on a National Random Sample of 413 Czech Families Caring for an Elderly Family Member in the Year 2010, as Part of Work on a Grant from the Czech Science Foundation (grant no. 403-09-1208). 